\title{
Presentación Dossier
}

\section{COMUNISMO CHILENO: \\ UN ÁREA HISTORIOGRÁFICA EN EXPANSIÓN}

Sergio Grez Toso*

Durante mucho tiempo, la historiografía del comunismo chileno se redujo casi exclusivamente a los aportes del profesor Hernán Ramírez Necochea sobre el Partido Comunista de Chile (PCCh) ${ }^{1} \mathrm{o}$ a aquellos de otros exponentes referidos al destacado líder obrero Luis Emilio Recabarren, fundador en 1912 del Partido Obrero Socialista (POS) devenido en PCCh en $1922^{2}$. Varios autores abordaron aspectos puntuales de la historia del comunismo criollo en libros o artículos sobre otros temas de historia social o historia política, pero no existía un corpus de obras que pudiera constituir un área de estudios específica con suficiente masa crítica. Como suele ocurrir, además de las obras de Ramírez Necochea, se disponía de manuales canónicos para los militantes que eran el contrapunto de las visiones características de la "leyenda negra" sobre el comunismo. No obstante, hacia fines de la década de 1970, el historiador británico Andrew Barnard marcó con su tesis doctoral un hito que, aunque en ese momento no tuvo mayores repercusiones, terminaría siendo reconocido como una inflexión fundamental ${ }^{3}$, abriendo paso dos décadas más tarde a una nutrida producción que ha logrado conformar un campo historiográfico pujante en Chile ${ }^{4}$.

* Dr. en Historia, académico de la Universidad de Chile, director de la revista Cuadernos de Historia. Santiago, Chile, ORCID ID: https://orcid.org/0000-0002-9704-1655. Correo electrónico: sergiogreztoso@gmail.com

1 Ramírez, 1984 (1 $1^{\text {a ed. }), ~ 2007, ~ V o l . ~ I I, ~ p p . ~ 151-467 . ~}$

2 Alegría, 1938 (1 $1^{\mathrm{a}}$ ed.), 1968 (2 ed.); Jobet, 1955; Godoy 1971, pp. 107-139; Witker, 1977; Ljubetic, 1992.

3 Barnard, 2017.

4 Véase los siguientes balances y reflexiones: Rojas Flores, 2000, pp. 1-79; Álvarez, 2010, pp. 11-30; Ulianova, 2010, pp. 261-287; Grez, 2011, pp. 7-20; Grez, 2012, pp. 13-21. Al final del libro editado por Ulianova, Loyola y Álvarez, 2012, se encuentra un anexo sobre "Fuentes y bibliografía para el estudio del Partido Comunista de Chile" muy completo. Véase, además, Manuel Loyola y Rolando Álvarez (eds.), 2014; Álvarez, 2019, pp. 121-140. 
Diversos factores explican la lenta reacción de la historiografía chilena al aporte precursor de Barnard. El golpe de Estado, la dictadura, la persecución de numerosos historiadores y cientistas sociales, el exilio y los lacerantes debates en el seno de la izquierda chilena bloquearon o retardaron el nacimiento de un área específica de estudios sobre el comunismo criollo que superara la historiografía de sesgo hagiográfico, devota y mistificadora. En la década de 1990, durante la "transición a la democracia" en Chile, de manera coincidente con la "caída de los muros" y la disolución de la Unión Soviética y del "socialismo real" en los países de Europa del Este, empezó a gestarse un nuevo escenario, mucho más favorable para el desarrollo de una sólida historiografía académica sobre el comunismo chileno. La apertura de los archivos soviéticos fue un hecho de la mayor trascendencia que fue aprovechado de manera brillante y generosa por la historiadora rusa avecindada en Chile, Olga Ulianova. Su aporte historiográfico y documental fue incalculable. La exhaustiva recopilación de documentos del archivo moscovita del Komintern sobre Chile, que puso a disposición del público lector en lengua castellana con la colaboración de Alfredo Riquelme, abrió un vastísimo horizonte de posibilidades de exploración historiográfica que es necesario seguir agradeciendo y aquilatando. Pero no fueron solo aportes documentales. Ulianova dejó -a pesar de su muerte prematura- abundantes trabajos basados en esa documentación y en su gran erudición, que han servido de base e inspiración a quienes cultivamos este tipo de estudios 5 . Paralelamente, otros historiadores como Jorge Rojas y Manuel Loyola se esforzaban por incentivar la reflexión de un pequeño núcleo de colegas sobre la necesidad de avanzar en un escenario hasta entonces poco favorable "hacia una historia de los comunistas chilenos"

No obstante, subsistían otros obstáculos que continuaron retardando el surgimiento de una nueva historia política desprendida de las limitaciones de la historia política tradicional. Paradójicamente, una traba importante fue el auge de la denominada "nueva historia social" o "nueva historia social popular" que, surgida en la década de 1980, alcanzó su zénit durante la siguiente y en los primeros años del siglo actual. La versión más radical (y hegemónica) de esta historiografía rechazaba y despreciaba la dimensión política formal de la historia, percibiéndola como un espacio conservador que había que superar, tanto

5 La obra de Olga Ulianova sobre el comunismo en Chile es muy vasta. Algunos títulos dan cuenta parcial de ello: Ulianova y Riquelme (eds.), 2005, 2009 y 2017. Además de los cinco estudios de su autoría incluidos en estos volúmenes, véase, entre otros: Ulianova, 2008a, pp. 99-164; Ulianova, 2008b, pp. 52-90; Ulianova, 2010, op. cit.

6 Loyola y Rojas, 2000, op. cit., passim. 
historiográfica como políticamente, para dar paso a la historia emancipadora, la historia social ${ }^{7}$. Superar la dicotomía historia política versus historia social tomó tiempo y prolongados esfuerzos ${ }^{8}$. No solo fue necesario criticar ciertas concepciones restrictivas que hacían escuela entre las nuevas generaciones interesadas por el estudio de la historia contemporánea, también fue preciso producir obras que pudieran ser consideradas como modelos alternativos al hegemónico en aquellos años ${ }^{9}$. Así, lentamente primero, y con mucha fuerza después de 2010, fue surgiendo un campo de estudios de nueva historia política $\mathrm{y}$, en su seno, uno más específico sobre el comunismo chileno. Como bien decía hacia 2009 Olga Ulianova, anunciando un movimiento cada vez más perceptible, "la historia política está de vuelta" ${ }^{10}$. Menos de un lustro más tarde, ya no cabían dudas, tal como quedó consignado en un balance historiográfico realizado por dos jóvenes historiadores. En el dio cuenta de la revitalización de la historia política en Chile mediante "la constitución de un mosaico entre diversas concepciones teóricas y metodológicas" que, a diferencia de lo ocurrido en Europa con esta área de estudios, se distanciarían en cuestiones centrales "tales como la mantención de perspectivas totalizantes de raigambre materialista-histórica". De allí entonces, que lo más interesante de esta nueva historiografía política sería, "además de su objeto de estudio (lo político), su afán crítico y revisionista"

Curiosamente, el retorno de la historia política en Chile encontró su mayor audiencia y número de cultores en aquellas mismas franjas etarias -jóvenesque diez o quince años antes habían abrazado con fervor el culto por lo social

\footnotetext{
Algunas expresiones críticas frente a estas concepciones en Rojas, 2000, op. cit.; Grez 2005, pp. 17-31; Ulianova, 2009, pp. 9-18.

8 Rolando Álvarez describe un aspecto de este fenómeno de la siguiente manera: “[...] los historiadores de la corriente de la "nueva historia social" depusieron al "obrero" como único actor popular, privilegiando las indagaciones sobre el denominado "bajo pueblo" y los sectores no organizados. En este aspecto destacó especialmente el influyente programa historiográfico de Gabriel Salazar. Solo algunos historiadores, como Jorge Rojas Flores y Sergio Grez Toso, continuaron la indagatoria sobre los trabajadores organizados. Sin embargo, tras un largo período en que parecía que estos especialistas estaban solos en esta cruzada, en los últimos diez años se ha renovado el interés por la historia sindical, incluida su fase más reciente, después del retorno de la democracia en 1990. Las movilizaciones sociales de 2011 constituyeron un momento de repolitización de la sociedad chilena que, de alguna u otra manera, se ha expresado en el campo historiográfico en el interés de rescatar el enfoque de clase para analizar la sociedad chilena", Álvarez, 2019, op. cit., p. 133.

9 Véase, entre otras: Rojas, 1993; Grez, 1998; Pinto, 1998; Pinto y Valdivia, 2001; Grez, 2007; Pinto, 2007; Grez, 2011; Grez, 2016.

10 Ulianova, 2009, op. cit.

11 Ponce y Pérez, 2013, pp. 453-476.
} 
"puro", supuestamente incontaminado por la política. Es altamente probable que un factor fundamental de este vuelco hayan sido los sucesos del "año bisagra" de 2011, con su irrupción de movimientos sociales en proceso de acelerada politización. La crítica intelectual, hasta ese momento poco escuchada, logró contar con un interlocutor social que, a su vez, estimuló a las nóveles camadas de historiadores e historiadoras en formación a ampliar su horizonte de posibilidades explorando nuevos caminos. Desde entonces, los estudios sobre el comunismo chileno se han multiplicado velozmente: numerosas tesis de pre y postgrado, ponencias en congresos, coloquios y simposios, artículos y libros, entre otras producciones ${ }^{12}$, dan cuenta de la configuración de una vigorosa área de estudios como parte de un fenómeno que también está presente en otros países latinoamericanos ${ }^{13}$.

El dossier que tenemos la satisfacción de presentar en Cuadernos de Historia, y que inaugura los expedientes temáticos en esta revista, es una muestra más de que la historia política en armonía con la historia social, intelectual y cultural está de vuelta, y que el comunismo chileno ocupa un lugar relevante en la historiografía nacional.

Rolando Álvarez, en "La desestalinización en las Juventudes Comunistas de Chile y la construcción de una cultura juvenil alternativa (1956-1964)", estudia la recepción que tuvo en el $\mathrm{PCCh}$, específicamente en su rama juvenil, el proceso de "desestalinización" iniciado en 1956 a partir del XX Congreso del Partido Comunista de la Unión Soviética. Álvarez sostiene que en Chile la desestalinización (moderada) "ofreció una versión mejorada del comunismo", convirtiéndose en un elemento que coadyuvó al crecimiento de las Juventudes Comunistas (JJ.CC). De acuerdo con este planteamiento, la influencia soviética en el partido chileno durante la desestalinización habría sido una parte fundamental en la elaboración comunista de una propuesta de cultura juvenil alternativa al capitalismo y al modelo norteamericano, cuya eclosión se produciría durante la década de 1960. Al igual que en otros textos de su autoría, Álvarez adopta una posición que apunta a la superación de la esterilizante dicotomía factores nacionales versus

12 Un ejemplo de la cantidad y variedad de esta nueva producción fue el Simposio "Historia del comunismo (Homenaje a Olga Ulianova)", realizado en el marco de las XIII Jornadas de Historia de Chile, Valdivia, Universidad Austral, 25 de octubre de 2017. Referencias a algunos de los nuevos exponentes de la historiografía del comunismo chileno en Álvarez, 2019, op. cit., p. 132.

13 Estos desarrollos pueden apreciarse de manera parcial, pero bastante ilustrativa, en cuatro libros colectivos: Concheiro; Modonesi y Crespo (coords.), 2007; Herrera (coord.), 2017; Valobra y Yusta (eds.), 2017; Palieraki y Herrera (comps.). A estos libros debe agregarse el reciente dossier coordinado por Grez, 2020, pp. 73-18. 
factores internacionales para explicar la evolución de los partidos comunistas (el chileno en este caso). Apoyándose en los planteamientos del historiador Silvio Pons, quien ha sostenido que en la historia del comunismo, la dimensión internacional fue un factor constituyente de su cultura política que incidió en su cosmovisión, en su lenguaje y sus valores, Álvarez sostiene que ello no significa desconocer la diversidad y especificidad de experiencias nacionales. Según su análisis, la influencia del proceso de desestalinización se habría llevado a cabo en las JJ.CC. chilenas con cierta flexibilidad, sin rechazar en bloque algunos aspectos de la cultura de masas, sino más bien resignificándolos, combinándose con las tradiciones culturales del movimiento obrero nacional de comienzos del siglo XX, con la herencia de la matriz marxista-leninista-estalinista característica del PCCh y con las repercusiones de las grandes transformaciones políticas y sociales que América Latina y Chile experimentaron durante el período de este estudio. Álvarez concluye con una observación que puede guiar tentativamente nuevas investigaciones, a saber, que la desestalinización no significó erradicar el estalinismo de la cultura política del comunismo chileno, puesto que en este legado había formado a generaciones de militantes del partido y había sido "un elemento muy importante en la construcción ideológica del comunismo como nueva civilización alternativa". No era posible destruir por completo el legado estalinista, sostiene Álvarez, pues "significaba poner en tela de juicio la forma de ver el mundo de la militancia comunista". Por ello, la desestalinización moderada "implicó apartarse de las formas más rígidas de estalinismo, pero no del conjunto de su sistema de prácticas e ideología". Huelga decir que esta convincente explicación podrá satisfacer las exigencias de una historiografía académica crítica, pero no las de los amantes de las historias canónicas y de las hagiografías colectivas.

En su contribución "Entre la III y la IV Internacional: hidalguismo, el comunismo disidente en Chile", Andrey Schelchkov aborda el estudio de la disidencia comunista organizada en el seno del PCCh hacia 1930 en base al material encontrado en el Archivo Nacional de la Historia Sociopolítica de Rusia (RGAPSI) y en el también moscovita Archivo de Henk Sneevliet ${ }^{14}$. Como es

14 Henk Sneevliet (1883-1942), conocido con el seudónimo de "Maring", comunista holandés que desarrolló actividades en su país y en las Indias Orientales Neerlandesas (Indonesia). Como emisario de la Internacional Comunista colaboró en la fundación del Partido Comunista de China en 1921. En Holanda integró el Comité Ejecutivo del Partido Comunista a partir de 1925, pero en 1927 rompió con este partido y con el Komintern. Fue fundador y principal dirigente del Partido Socialista Revolucionario (PSR) holandés (1929), ocupando el único curul parlamentario de este partido en la Cámara de Representantes. Abrazó las ideas de la oposición de izquierda al estalinismo. En agosto de 1933, el PSR firmó la "Declaración de los Cuatro" junto con 
sabido, la corriente liderada, desde fines de la década de 1920, por el senador Manuel Hidalgo en el seno del PCCh que se opuso a la intervención autoritaria del Secretariado Sudamericano (SSA)/Buró Sudamericano (BSA) en los asuntos internos del PCCh, es considerada frecuentemente como "trotskista", sin mayores análisis ni matices. Schelchkov, en sintonía con los avances historiográficos de las últimas décadas, sostiene que, si bien este sector después de intentar vanamente demostrar su lealtad a la Komintern fue acogido por el movimiento trotskista internacional que, "aunque receloso de su eventual inconsistencia doctrinaria, vio en el hidalguismo la posibilidad de formar un partido fuerte y potencialmente hegemónico" en Chile. Los hidalguistas, por su parte, a pesar de su laxitud ideológica, "encontraron en el trotskismo una justificación internacional a su disidencia y formalmente adoptaron la mayor parte de su retórica y doctrina", decidiendo en el momento de su constitución como Izquierda Comunista (marzo de 1933) adherir a la Oposición de Izquierda Internacional. No obstante, como queda demostrado, estos militantes -salvo un grupo muy pequeño que algunos años más tarde formaría el Partido Obrero Revolucionario (POR), de reconocido sello trotskista- nunca alcanzaron definiciones tan depuradas que permitieran catalogarlos como ortodoxos seguidores de los postulados de Lev Trotsky.

Uno de los aportes más significativos de Schelchkov es, precisamente, su planteamiento sobre la ambigüedad de los comunistas "oposicionistas de izquierda" chilenos respecto del Secretariado Internacional trotskista en camino a la formación de la IV Internacional, "así como su perseverancia en tomar decisiones políticas independientes de ambas internacionales". Lo que entregaría luces -según una de las lecturas que podemos hacer de este texto-acerca de la temprana disolución de la Izquierda Comunista (1936) y el ingreso de sus principales dirigentes al Partido Socialista de Chile. A pesar de su "trotskismo a medio pelo", ubicado entre la III y la IV Internacional, "sin haber sido aceptado cabalmente en ninguna de las dos" concluye Schelchkov, el hidalguismo jugaría posteriormente un papel importante en la izquierda marxista chilena, "al ser portador de una visión marxista más amplia y plural, más creativa, sin las limitaciones estrictas y cerradas provenientes tanto de la ortodoxia trotskista como de la anti trotskista, prosoviética". Esta conclusión trasciende, naturalmente, el estudio de la corriente comunista en sus distintas

la Liga Comunista Internacional de León Trotsky y otras organizaciones, en la perspectiva de la fundación de una nueva Internacional. No obstante, en 1938, "Maring" y el PSR rompieron con el trotskismo en el momento de la fundación de la IV Internacional. Por sus actividades en la resistencia, Sneevliet fue fusilado por los ocupantes nazis en 1942. 
variantes, iluminando el estudio de otras izquierdas en la tierra de Luis Emilio Recabarren y Salvador Allende.

En "El funeral de Fonseca: estrategias políticas en la ilegalidad comunista, julio de 1949", Jorge Rojas Flores reconstituye cuidadosamente las exequias del secretario general del PCCh Ricardo Fonseca, en el contexto de la proscripción política que sufría este partido como resultado de la aplicación de la Ley de Defensa Permanente de la Democracia ("Ley Maldita”). El análisis de la organización de la ceremonia fúnebre le permite probar cómo esta se transformó en una herramienta política con la que el PCCh buscó incidir en el adverso escenario, "demostrando la fuerza que todavía podía desplegar y reforzando la propia identidad partidaria, afectada por su virtual marginación de la vida política". La minuciosa preparación de las exequias, el carácter monumental de su ritualidad y el impacto que produjo en variados actores políticos son expuestos y analizados de manera detallada en una perspectiva de larga duración comparativa con otros grandes funerales de líderes del PCCh, como los de Luis Emilio Recabarren (1924), Galo González (1958), Elías Lafertte (1961), Pablo Neruda (1973) y Gladys Marín (2005), además de los de ciertos cuadros de relieve más modesto. Rojas concluye su estudio señalando que el funeral de Fonseca, además de expresar la cultura política comunista caracterizada con una fuerte identidad, "se transformó en un acto político en sí mismo, por el efecto que se quiso provocar a través de él", revirtiendo en parte el desfavorable escenario de exclusión institucional mediante las ceremonias fúnebres de quien había sido el secretario general del PCCh.

El artículo "La Universidad de Chile según el académico y militante comunista Hernán Ramírez Necochea (1960-1964)" de Gorka Villar Vásquez se sitúa en la intersección entre la nueva historia política y la historia intelectual a fin de analizar la idea de Universidad formulada por el mencionado académico, historiador y dirigente comunista, a partir de su experiencia como docente e investigador en la principal Universidad del país. Según este análisis, Ramírez concibió la Universidad como un espacio de disputa ideológica de los sectores populares y progresistas con la clase dominante y el imperialismo cultural norteamericano, reflejado, entre otras formas, por su financiamiento a ciertas instancias de esta Universidad. No está de más recordar que, pocos años después del período cubierto por el análisis de este artículo, en tanto decano de la Facultad de Filosofía y Educación, Ramírez Necochea jugaría un rol trascendente en la democratización de la enseñanza superior mediante el proceso de reforma universitaria de fines de la década de 1960 y comienzos de la de 1970. Para corroborar su hipótesis, Villar estudia la relación entre el PCCh y la Universidad a fines de la década de 1950 e inicios de la siguiente, reconstruye la biografía académica y política de Ramírez Necochea y analiza su 
concepto de Universidad a través de la revisión de variadas fuentes que, además de las escritas (memorias, documentos inéditos conservados en el Archivo Central Andrés Bello de la Universidad de Chile, producción historiográfica del historiador comunista, entrevistas, prensa militante y universitaria de la época), incluyen varias entrevistas a personas de su entorno.

Manuel Loyola en "La función de lo soviético en Chile. La actuación editorial del inmigrante ucraniano Boris Orjikh" analiza la relación entre el impacto y significado que tuvo en Chile la Revolución de octubre y la construcción y función propagandística de la Unión Soviética en el medio intelectual y político chileno en las décadas de 1930 y 1940, tomando como ejemplo de análisis la labor editorial desarrollada entre 1933 y 1937 por el inmigrante ucraniano Boris Orjikh, destinada a "hacer de lo soviético el símbolo de la nueva ciudad de la humanidad". Loyola pone el énfasis en factores que, desde su perspectiva, incidieron tanto para explicar la popularidad de la experiencia soviética en ciertos medios (incluyendo la administración estatal controlada por coaliciones políticas de orientación frentepopulista), como "la perdurabilidad de lo soviético en el imaginario de parte importante de la izquierda chilena", dando cuenta, de paso, de la aparición de prácticas político-editoriales que habrían incidido en el desarrollo de la cultura comunista chilena de aquella época. Tal vez lo más relevante de las conclusiones de este autor dice relación con que lo soviético, de acuerdo con su análisis de la folletería difundida por Orjikh, cerraba el círculo de una "perspectiva de verdad", "la verdad de un saber social fundado en una evolución que, con ahínco, había buscado dar con el sujeto y el saber que convirtieran en realidad los signos benéficos inscritos en el despliegue eterno de las fuerzas de la naturaleza y de la historia", sesgo teleológico de lo soviético promovido por los impresos de Orjikh y de otros editores revolucionarios de aquel tiempo que, "a pesar de lo acotado de su producción, perduraría y determinaría, consolidado a poco andar como marxismo-leninismo, lo principal de la ideología comunista del siglo XX".

Cerrando este dossier, Raquel Aránguez Muñoz, en su texto "Los jóvenes debemos disputar el poder. Las Juventudes Comunistas de Chile y el movimiento estudiantil universitario (2000-2011)", busca identificar las transformaciones en la identidad comunista generada por más de una década de movilizaciones estudiantiles, identificando al mismo tiempo elementos de la influencia de la rama juvenil del PCCh. sobre el mismo movimiento estudiantil. Situándose desde una perspectiva de historia social del comunismo, Aránguez sostiene que los cambios experimentados a partir de esta relación ponen de relieve la importancia que adquirió el espacio estudiantil para las JJ.CC. puesto que desde este se desarrollaron propuestas programáticas que cuestionaron el neoliberalismo en la educación, alcanzando su máxima expresión en las grandes movilizaciones de 
2011. Durante el período estudiado, las JJ.CC. habrían desarrollado un sentido pragmático debido a la necesidad de abrirse a otros actores, terminando con el aislamiento en que se encontraban desde los primeros años de la década de 1990. Aránguez subraya el doble aspecto de la relación entre las JJ.CC. y el movimiento estudiantil, pues la influencia de este habría contribuido fuertemente a la transformación de la identidad de la militancia juvenil del PCCh, transitando del sello decididamente obrero y poblacional de los últimos años de lucha contra la dictadura a uno de carácter estudiantil. Por su parte, las JJ.CC. habrían aportado al desarrollo del movimiento estudiantil universitario al ayudarlo a identificar y criticar las políticas neoliberales en la educación para, enseguida, levantar un programa enfocado en la defensa de la educación pública centrado en la democratización de la universidad, su financiamiento y una reforma de la educación superior. Sin negar las tensiones propias de esferas de naturaleza diferente, el ejercicio historiográfico de Raquel Aránguez logra ofrecernos una articulación armoniosa entre lo social y lo político, signo inequívoco de que las dicotomías esterilizantes de hace algunos años se encuentran en retirada, especialmente en las nuevas generaciones.

La nueva historia política y la historiografía del comunismo gozan de buena salud en Chile.

Santiago, primavera austral de 2020.

\section{Bibliografia}

Alegría, Fernando, Recabarren, Santiago, Editorial Antares, 1938 ( $1^{\mathrm{a}}$ ed.), Santiago, Editora Santiago, 1968 ( $2^{\mathrm{a}}$ ed.).

Álvarez Vallejos, Rolando, "Historia, historiografía y memorias del comunismo chileno en la primera década del siglo XXI. Un ensayo bibliográfico", Prólogo del libro de Viviana Bravo Vargas, ;Con la Razón y la Fuerza, Venceremos! La Rebelión Popular y la Subjetividad Comunista en los '80, Santiago, Ariadna Ediciones, 2010, pp. 11-30.

Álvarez VALLEJos, Rolando, "La historiografía sobre las izquierdas en Chile: un campo en expansión", Archivos, año VII, N 14, Buenos Aires, marzo de 2019, pp. 121-140.

BARNARD, ANDREW, "The Chilean Communist Party, 1922-1947", thesis present for the degree of Doctor of Philosophy in the University of London, London, University College, University of London, december 1977. Publicación en castellano: Andrew Barnard, El Partido Comunista de Chile 1922-1947, Santiago, Ariadna Ediciones, 2017.

Concheiro Bórquez, Elvira; Massimo Modonesi y Horacio Crespo (coords.), El comunismo: otras miradas desde América Latina, México, Universidad Autónoma de 
México - Centro de Investigaciones Interdisciplinarias en Ciencias y Humanidades, 2007.

Godoy Urrutia, CÉSAR, “Vida y obra de Recabarren”, Principios, No 141-142, Santiago, septiembre-diciembre de 1971, pp. 107-139.

Grez Toso, Sergio, "Comunismo chileno e historiografía: un par de observaciones", en Olga Ulianova; Manuel Loyola y Rolando Álvarez (eds.), 1912-2012 El siglo de los comunistas chilenos, Santiago, Instituto de Estudios Avanzados Universidad de Santiago de Chile, 2012, pp. 13-21.

Grez Toso, Sergio, "Comunismo sudamericano. Nuevas miradas historiográficas", Avances del CESOR, Vol. 17, N²2, Rosario, junio de 2020, pp. 73-18; https://ojs. rosario-conicet.gov.ar/index.php/AvancesCesor/issue/view/100

Grez Toso, Sergio, "Escribir la historia de los sectores populares. ¿Con o sin la política incluida? A propósito de dos miradas a la historia social (Chile, siglo XIX)", Política, Vol. 44, Santiago, Otoño de 2005, pp. 17-31; https://revistapolitica.uchile.cl/index. $\mathrm{php} / \mathrm{RP} / \mathrm{article} / \mathrm{view} / 25600$

Grez Toso, Sergio, De la "regeneración del pueblo" a la huelga general. Génesis y evolución histórica del movimiento popular en Chile (1810-1910), Santiago, Dirección de Bibliotecas, Archivos y Museos, Centro de Investigaciones Diego Barros Arana-Red Internacional del Libro, 1998 (1 ${ }^{\mathrm{a}}$ ed.).

Grez Toso, Sergio, El Partido Democrático de Chile. Auge y ocaso de una organización política popular (1887-1891), Santiago, Lom Ediciones, 2016.

Grez Toso, Sergio, Historia del comunismo en Chile. La era de Recabarren (19121924), Santiago, Lom Ediciones, 2011a.

Grez Toso, Sergio, Los anarquistas y el movimiento obrero. La alborada de "la Idea" en Chile, 1893-1915, Santiago, Lom Ediciones, 2007.

Herrera González, PAtricio (coord.), El comunismo en América Latina. Experiencias militantes, intelectuales y transnacionales (1917-1955), Valparaíso, Universidad de Valparaíso, 2017.

JoBEt, Julio CÉSAR, Recabarren y los orígenes del movimiento obrero y del socialismo chileno, Santiago, Prensa Latinoamericana, 1955 ( $1^{\mathrm{a}} \mathrm{ed}$.).

LuUbetic, Iván, Don Reca, Santiago, ICAL, 1992.

Loyola, MANuel y Jorge Rojas Flores (comps.), Hacia una historia de los comunistas chilenos, Santiago, Impresora Valus, 2000, pp. 1-79.

Loyola, Manuel y Rolando Álvarez (eds.), Un trébol de cuatro hojas. Las Juventudes Comunistas de Chile en el siglo XX, Santiago, Ariadna Ediciones - Editorial América en Movimiento, 2014.

Palieraki, Eugenia y Carlos Herrera (comps.), La revolución rusa y América Latina, Valparaíso, Editorial América en Movimiento (en proceso editorial).

Pinto Vallejos, Julio y Verónica Valdivia O., ¿Revolución proletaria o querida chusma? Socialismo y Alessandrismo en la pugna por la politización pampina (1911-1932), Santiago, Lom Ediciones, 2001. 
Pinto Vallejos, Julio, Desgarros y utopías en la pampa salitrera. La consolidación de la identidad obrera en tiempos de la cuestión social (1890-1923), Santiago, Lom Ediciones, 2007.

Pinto Vallejos, Julio, Trabajos y rebeldías en la pampa salitrera. El ciclo del salitre y la reconfiguración de las identidades populares (1850-1900), Santiago, Editorial Universidad de Santiago, 1998.

Ponce LóPEZ, IGNACIO Y ANÍBAL PÉREz, "La revitalización de la historiografía política chilena”, Polis, Revista Latinoamericana, Vol. 12, N³6, Santiago, 2013, pp. 453-476; https://scielo.conicyt.cl/scielo.php?script=sci_arttext\&pid=S0718-65682013000300020.

Ramírez Necochea, Hernán, Origen y formación del Partido Comunista de Chile. Ensayo de historia politica y social de Chile, Moscú, Editorial Progreso, 1984 (1 ${ }^{\mathrm{a}}$ ed.). Posteriormente esta obra fue incluida en Hernán Ramírez Necochea, Obras escogidas, Vol. II, Santiago, Lom Ediciones, 2007, pp. 151-467.

Rojas Flores, Jorge, "Historia, historiadores y comunistas chilenos", en Manuel Loyola y Jorge Rojas Flores (comps.), Hacia una historia de los comunistas chilenos, Santiago, Impresora Valus, 2000, pp. 1-79.

Rojas Flores, JoRge, La dictadura de Ibáñez y los sindicatos (1927-1931), Santiago, Dirección de Bibliotecas, Archivos y Museos, 1993.

Ulianova, Olga y Alfredo Riquelme Segovia (eds.), Chile en los archivos soviéticos 1922-1991, Tomo 1: Komintern y Chile 1922-1931, Tomo 2: Komintern y Chile 1931-1935, Tomo 3: Komintern y Chile 1935-1941, Santiago, Ediciones de la Dirección de Bibliotecas, Archivos y Museos, Centro de Investigaciones Diego Barros Arana-Lom Ediciones, 2005, 2009 y 2017, respectivamente.

Ulianova, Olga, "Develando un mito: emisarios de la Internacional Comunista en Chile", Historia, N 41, Vol. I, Santiago, enero-junio de 2008a, pp. 99-164.

Ulianova, Olga, "El comunismo chileno a través de los archivos soviéticos", en Augusto Varas; Alfredo Riquelme y Marcelo Casals (eds.), El Partido Comunista en Chile. Una historia presente, Santiago, Catalonia - Universidad de Santiago de Chile - FLACSO Chile, 2010, pp. 261-287.

Ulianova, Olga, "Entre el auge revolucionario y los abismos del sectarismo: el PC chileno y el Buró Sudamericano de la Internacional Comunista en 1932-1933”, en Rolando Álvarez; Augusto Samaniego y Hernán Venegas (eds.), Fragmentos de una historia. El Partido Comunista de Chile en el siglo CC. Democratización, clandestinidad, rebelión (1912-1994), Santiago, Ediciones ICAL, 2008b, pp. 52-90.

Ulianova, Olga, "La historia política está de vuelta" en Olga Ulianova (comp.), Redes políticas y militancias. La historia política está de vuelta, Santiago, Ariadna Ediciones, 2009, pp. 9-18.

Valobra, Adriana y Mercedes Yusta (eds.), Queridas camaradas. Historias iberoamericanas de mujeres comunistas, Buenos Aires, Miño y Dávila Editores, 2017.

Witker, Alejandro, Los trabajos y los días de Recabarren, La Habana, Casa de las Américas, 1977. 